Journal of Mathematics and Statistics 2 (1): 334-338, 2006

ISSN 1549-3644

(C) 2006 Science Publications

\title{
Constrained Single Period Stochastic Uniform Inventory Model With Continuous Distributions of Demand and Varying Holding Cost
}

\author{
${ }^{1}$ Hala, A. Fergany and ${ }^{2}$ M. E. El-Saadani \\ ${ }^{1}$ Department of Mathematical Statistics, Faculty of Science, Tanta University, Tanta, Egypt \\ ${ }^{2}$ Department of Mathematical Statistics, Faculty of Education, Suez Canal University, Suez, Egypt
}

\begin{abstract}
This paper derives the single period stochastic inventory model with continuous distributions of demand and the holding unit cost is a function of the purchased (ordered) quantity. The objective is to find the optimal purchased quantity which minimizes the expected total cost for the period under a restriction on the expected varying holding cost when the demand during the period follows the uniform, the exponential and the Laplace distributions, using the Lagrange multiplier approach. Some special cases are deduced and illustrative numerical examples with some graphs are added.
\end{abstract}

Key words: Stochastic inventory model, zero lead time, varying holding cost, continuous distribution

\section{INTRODUCTION}

The single period model is concerned with the planning and control of inventory items for which only one replenishment opportunity exists. Unconstrained single period stochastic inventory systems with constant unit costs treated by Gould ${ }^{[1]}$, Nahmias ${ }^{[2]}$ and Tersine ${ }^{[3]}$. Also, Silver ${ }^{[4]}$ examined the single period model when the demand during the period normally distributed. Single period models involving a number of items connected by one or more constraints can take a variety of forms. Hadley ${ }^{[5]}$ studied constrained multiple item single period inventory problems with continuous distribution of demand and constant unit costs, using the Lagrange multiplier approach.

The probabilistic single item single source zero lead time inventory systems with instantaneous and uniform rates of demand distribution have been discussed by Fabrycky ${ }^{[6]}$. Recently, Abou-El-Ata ${ }^{[7]}$ and Fergany ${ }^{[8]}$ introduced a probabilistic single-item inventory problem with varying order cost and zero lead time under two restrictions, using geometric programming approach.

This paper investigate the single period stochastic uniform inventory model that considering varying holding unit cost, a restriction on the expected holding cost and the demand during the period is a continuous random variable. Our objective is to determine the optimal purchase (order) quantity, which minimizes the relevant expected total cost for the period, when the demand during that period follows the uniform, the exponential and the Laplace distributions. Finally, some special cases, which have been previously published and numerical illustrative example are added.

Assumptions and Notations: The following assumptions are made for developing the model:
* The system is the single period and zero lead time. That is, an item is purchased once only to satisfy the demand of a specific period of time.

* The number of units to purchase for inventory at the beginning of the period is $Q$ (the decision variable) and the stock level decreases at a uniform rate over the period

* The demand $x$ during that period is continuous random variable with known probability density function.

* There is no order (setup) cost.

The following notations are adopted for developing our model:

$f(x)=$ The probability density function of the demand $x$ during the period,

$E(x) \quad=$ The expected value of $x$,

$F(x)=$ The cumulative distribution function of $x$,

$R(x) \quad=$ The reliability function,

$\mathrm{Q}^{*} \quad=$ The optimal purchased quantity,

$\mathrm{p}\left(\mathrm{x} \leq \mathrm{Q}^{*}\right)=$ The probability of satisfying all the demand during the period if $Q^{*}$ units are purchased at the start of the period,

$\mathrm{p}\left(\mathrm{x}>\mathrm{Q}^{*}\right)=$ The probability of shortage,

$\mathrm{c}_{\mathrm{p}} \quad=$ The purchase unit cost,

$\mathrm{c}_{\mathrm{h}} \quad=$ The holding unit cost,

$C_{h}(Q)=c_{h} Q^{\beta}=$ The varying holding unit cost, $0 \leq \beta \leq 1$,

$\mathrm{c}_{\mathrm{s}} \quad=$ The shortage unit cost,

$\mathrm{E}(\mathrm{PC})=$ The expected purchase cost for the period,

$\mathrm{E}(\mathrm{HC})=$ The expected holding cost for the period,

$\mathrm{E}(\mathrm{SC})=$ The expected shortage cost for the period,

$\mathrm{E}(\mathrm{TC})=$ The expected total cost for the period,

$K=$ The limitation on the expected varying holding cost for the period.

Corresponding Author: Hala, A. Fergany, ${ }^{1}$ Department of Mathematical Statistics, Faculty of Science, Tanta University, Tanta, Egypt 


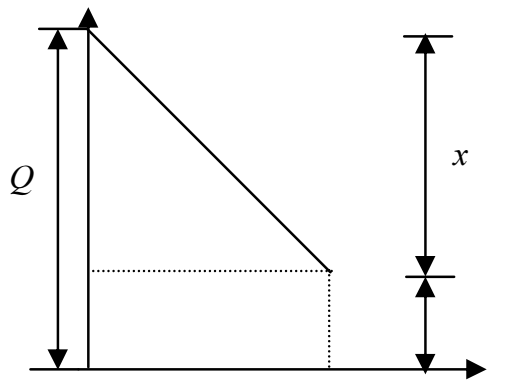

(I) $x<Q$

(Holding)

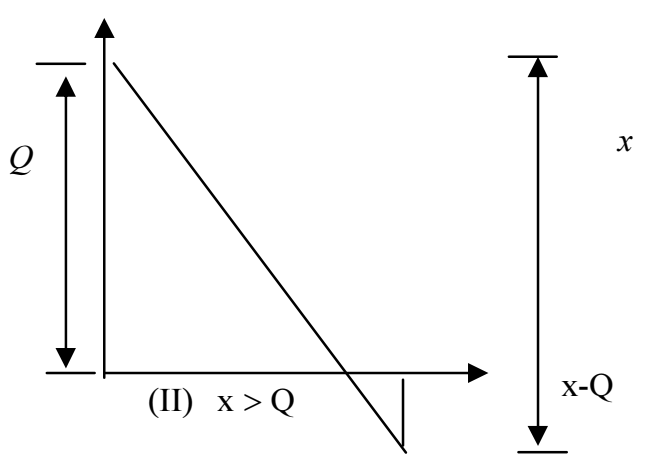

(Shortage)

Fig. 1: Single period uniform inventory model

Development of the expected total cost function:

A general outline for analyzing most stochastic inventory problems is the following:

* Develop an expression for the cost incurred as a function of both the random variable $x$ and the decision variable $Q$.

* Determine the expected value of this expression with respect to the probability density function of demand.

* Determine $\mathrm{Q}^{*}$ that minimizes the relevant expected total cost.

Thus, depending on the amount demanded $x$ and the quantity purchased $Q$, the inventory position after demand occurs may be either positive (holding) or negative (shortage). These two situations are shown in Figure. 1.

Now, consider that:

$\mathrm{H}(Q, x)=$ The random variable represents the amount in inventory at the end of the period,

and $\mathrm{S}(Q, x)=$ The random variable represents the shortage quantity at the end of the period.

Then, in the first situation in Figure 1 we have:

$\mathrm{H}(Q, x)=\mathrm{Q}-\frac{\mathrm{x}}{2} \quad$ and $\mathrm{S}(Q, x)=0$

Also, in the second situation of Figure. 1 we get:

$\mathrm{H}(Q, x)=\frac{\mathrm{Q}^{2}}{2 \mathrm{x}} \quad$ and $\mathrm{S}(Q, x)=\frac{(\mathrm{x}-\mathrm{Q})^{2}}{2 \mathrm{x}}$

$H(Q, x)= \begin{cases}Q-\frac{x}{2} & \text { for } x \leq Q \\ \frac{Q^{2}}{2 x} & \text { for } x>Q\end{cases}$

and
$S(Q, x)=\left\{\begin{array}{cc}0 & \text { for } x \leq Q \\ \frac{(x-Q)^{2}}{2 x} & \text { for } x>Q\end{array}\right.$

Therefore, the expected purchase, the expected holding and the expected shortage costs for the period respectively are given by:

$\mathrm{E}(\mathrm{PC})=\mathrm{c}_{\mathrm{p}} \int_{0}^{\infty} \mathrm{Q} \mathrm{f}(\mathrm{x}) \mathrm{dx}={ }^{c_{p}} Q$

$\mathrm{E}(\mathrm{HC})=\mathrm{c}_{\mathrm{h}} \mathrm{Q}^{\beta}\left[\int_{0}^{\mathrm{Q}}\left(\mathrm{Q}-\frac{\mathrm{x}}{2}\right) \mathrm{f}(\mathrm{x}) \mathrm{dx}+\int_{\mathrm{Q}}^{\infty} \frac{\mathrm{Q}^{2}}{2 \mathrm{x}} \mathrm{f}(\mathrm{x}) \mathrm{dx}\right]$

$\mathrm{E}(\mathrm{SC})=\mathrm{c}_{\mathrm{s}} \int_{\mathrm{Q}}^{\infty} \frac{(\mathrm{x}-\mathrm{Q})^{2}}{2 \mathrm{x}} \mathrm{f}(\mathrm{x}) \mathrm{dx}$

Hence, the expected total cost for the period is:

$\mathrm{E}(\mathrm{TC})={ }^{c_{p}} Q+$

$c_{h} Q^{\beta}\left[\int_{0}^{Q}\left(Q-\frac{x}{2}\right) f(x) d x+\int_{Q}^{\infty} \frac{Q^{2}}{2 x} f(x) d x\right]$

$+c_{s} \int_{Q}^{\infty} \frac{(x-Q)^{2}}{2 x} f(x) d x$

Our objective is to minimize the function (4) subject to the following constraint:

$\mathrm{E}(\mathrm{HC}) \leq K$

To solve this problem we can use the Lagrange multiplier approach. We introduce a Lagrange multiplier $\lambda$ and form the function:

$\mathrm{L}=\mathrm{E}(\mathrm{TC})+\lambda[\mathrm{E}(\mathrm{HC})-K]$

where $\lambda=0$ if $\mathrm{E}(\mathrm{HC})-\mathrm{K}<0, \lambda>0$

if $\mathrm{E}(\mathrm{HC})-K=0$,

then $\lambda[\mathrm{E}(\mathrm{HC})-\mathrm{K}]=0$ 
The optimal value $\mathrm{Q}$ *requires that :

$$
\frac{\partial L}{\partial Q}=0
$$

which gives:

$$
\begin{aligned}
& \mathrm{c}_{\mathrm{p}}+(1+\lambda)(1+\beta) \mathrm{c}_{\mathrm{h}} \mathrm{Q}^{\beta} \mathrm{F}(\mathrm{Q}) \\
& +\frac{(1+\lambda)(2+\beta) \mathrm{c}_{\mathrm{h}}}{2} \mathrm{Q}^{\beta+1} \int_{\mathrm{Q}}^{\infty} \frac{\mathrm{f}(\mathrm{x})}{\mathrm{x}} \mathrm{dx} \\
& -\frac{(1+\lambda) \beta \mathrm{c}_{\mathrm{h}}}{2} \mathrm{Q}^{\beta-1} \int_{0}^{\mathrm{Q}} \mathrm{xf}(\mathrm{x}) \mathrm{dx} \\
& +\mathrm{c}_{\mathrm{s}} \mathrm{Q} \int_{\mathrm{Q}}^{\infty} \frac{\mathrm{f}(\mathrm{x})}{\mathrm{x}} \mathrm{dx}-\mathrm{c}_{\mathrm{s}} \mathrm{R}(\mathrm{Q})=0 .
\end{aligned}
$$

Hence $Q^{*}$ is the solution of the following equation:

$$
\begin{aligned}
& c_{p}+\mathrm{AQ}^{* \beta} \mathrm{F}\left(\mathrm{Q}^{*}\right)+\left(\mathrm{BQ}^{* \beta+1}+\mathrm{c}_{\mathrm{s}} \mathrm{Q}^{*}\right) \int_{\mathrm{Q}^{*}}^{\infty} \frac{\mathrm{f}(\mathrm{x})}{\mathrm{x}} \mathrm{dx} \\
& -\mathrm{CQ}^{* \beta-1} \int_{0}^{\mathrm{Q}^{*}} \mathrm{xf}(\mathrm{x}) \mathrm{dx}-\mathrm{c}_{\mathrm{s}} \mathrm{R}\left(\mathrm{Q}^{*}\right)=0,
\end{aligned}
$$

where $\quad \mathrm{A}=(1+\lambda)(1+\beta) \mathrm{c}_{\mathrm{h}}, \quad \mathrm{B}=\frac{(1+\lambda)(2+\beta) \mathrm{c}_{\mathrm{h}}}{2}$ and $\mathrm{C}=\frac{(1+\lambda) \beta \mathrm{c}_{\mathrm{h}}}{2}$, by testing different values of $\lambda$, it is possible to determine the optimum purchase quantity $\mathrm{Q}^{*}$ that meet the requirement of the constraining condition $\mathrm{E}(\mathrm{HC})$. The iterative process requires that $\lambda$ be set equal to zero and small increments be added to it until the problem constraint is met for the different values of $\beta$.

The optimal value $Q^{*}>0$ obtained from (9) minimizes (4), where

$$
\begin{aligned}
& \frac{\mathrm{d}^{2} \mathrm{E}(\mathrm{TC})}{\mathrm{dQ}^{2}}=\beta(\beta+1) \mathrm{c}_{\mathrm{h}} \mathrm{Q}^{\beta-1} \mathrm{~F}(\mathrm{Q})+ \\
& \frac{\beta(\beta+3)+2}{2} \mathrm{c}_{\mathrm{h}} \mathrm{Q}^{\beta} \int_{\mathrm{Q}}^{\infty} \frac{1}{\mathrm{x}} \mathrm{f}(\mathrm{x}) \mathrm{dx} \\
& +\frac{\beta(1-\beta)}{2} \mathrm{c}_{\mathrm{h}} \mathrm{Q}^{\beta-2} \int_{0}^{\mathrm{Q}} \mathrm{xf}(\mathrm{x}) \mathrm{dx}+\mathrm{c}_{\mathrm{s}} \int_{\mathrm{Q}}^{\infty} \frac{1}{\mathrm{x}} \mathrm{f}(\mathrm{x}) \mathrm{d} \mathrm{x}>0 .
\end{aligned}
$$

Standard probability distributions such as the uniform, the exponential and the Laplace distributions are frequently assumed for the demand during the period. The exact solution of the optimal purchase quantity can be derived when the demand follows these distributions as followes:

* Demand during the period follows the uniform distribution

Assume that the demand during the period follows the uniform distribution with mean $\frac{b}{2}$, then

$$
E(x)=\frac{b}{2}, \quad F(Q)=\frac{Q}{b}, \quad R(Q)=1-\frac{Q}{b}
$$

Substituting in equation (9), we get :

$$
\left(\mathrm{A}-\frac{\mathrm{C}}{2}\right) \mathrm{Q}^{\beta+1}+\mathrm{BQ}^{\beta+1} \ln \frac{\mathrm{b}}{\mathrm{Q}}+\mathrm{c}_{\mathrm{s}} \mathrm{Q}\left(1+\ln \frac{\mathrm{b}}{\mathrm{Q}}\right)+\mathrm{b}\left(\mathrm{c}_{\mathrm{p}}-\mathrm{c}_{\mathrm{s}}\right)=0
$$

where:

$$
\begin{aligned}
& \int_{0}^{Q} x f(x) d x=\int_{0}^{Q} \frac{x}{b} d x=\frac{Q^{2}}{2 b} \quad \text { and } \\
& \int_{Q}^{\infty} \frac{f(x)}{x} d x=\int_{Q}^{b} \frac{1}{x b} d x=\frac{1}{b} \ln \frac{b}{Q}
\end{aligned}
$$

Therefore, when the demand during the period uniformly distributed the optimal inventory policy is the solution of the following equation:

$$
\left(\mathrm{A}_{1}+\mathrm{B} \ln \frac{\mathrm{b}}{\mathrm{Q}^{*}}\right) \mathrm{Q}^{* \beta+1}+\mathrm{c}_{\mathrm{s}} \mathrm{Q}^{*} \ln \frac{\mathrm{eb}}{\mathrm{Q}^{*}}+\mathrm{b}\left(\mathrm{c}_{\mathrm{p}}-\mathrm{c}_{\mathrm{s}}\right)=0
$$

Where $\mathrm{A}_{1}=\frac{1}{4}(1+\lambda)(4+3 \beta) \mathrm{c}_{\mathrm{h}}$, and

the minimum expected total cost for the period is: $\min E(T C)=$

$$
\left(c_{p}-c_{s}\right) Q^{*}+\frac{c_{s} b}{4}+\frac{c_{h} Q^{* \beta}+c_{s}}{2 b}\left(\frac{3 Q^{* 2}}{2}+Q^{* 2} \ln \frac{b}{Q^{*}}\right)
$$

* Demand during the period follows the exponential distribution

If the demand during the period exponentially distributed with mean $\mu$ and standard deviation $\mu$, then we have

$\mathrm{E}(\mathrm{x})=\mu \quad, \quad \mathrm{F}(\mathrm{Q})=1-\mathrm{e}^{-\frac{\mathrm{Q}}{\mu}}, \quad \mathrm{R}(\mathrm{Q})=\mathrm{e}^{-\frac{\mathrm{Q}}{\mu}}$ and $\int_{0}^{\mathrm{Q}} \mathrm{xf}(\mathrm{x}) \mathrm{dx}=\int_{0}^{\mathrm{Q}} \frac{\mathrm{x}}{\mu} \mathrm{e}^{-\frac{\mathrm{x}}{\mu}} \mathrm{dx}=\mu \mathrm{F}(\mathrm{Q})-\mathrm{Q} \mathrm{R}(\mathrm{Q})$

also, $\int_{\mathrm{Q}}^{\infty} \frac{\mathrm{f}(\mathrm{x})}{\mathrm{x}} \mathrm{dx}=\int_{\mathrm{Q}}^{\infty} \frac{1}{\mathrm{x} \mu} \mathrm{e}^{-\frac{\mathrm{x}}{\mu}} \mathrm{dx}=\frac{1}{\mu} \Gamma\left(0, \frac{\mathrm{Q}}{\mu}\right)$

Where $\Gamma(\mathrm{a}, \mathrm{z})=\int_{\mathrm{z}}^{\infty} \mathrm{t}^{\mathrm{a}-1} \mathrm{e}^{-\mathrm{t}} \mathrm{dt}$, is the incomplete gamma function.

Substituting in equation (9), the optimal purchase quantity $\mathrm{Q}^{*}$ is the solution of the following equation:

$\mathrm{c}_{\mathrm{p}}+\left[\mathrm{A} \mathrm{Q}^{* \beta}-\mu \mathrm{C} \mathrm{Q}^{* \beta-1}\right]$

$\mathrm{F}\left(\mathrm{Q}^{*}\right)+\frac{1}{\mu}\left(\mathrm{BQ}^{* \beta+1}+\mathrm{c}_{\mathrm{s}} \mathrm{Q}^{*}\right) \Gamma\left(0, \frac{\mathrm{Q}^{*}}{\mu}\right)$

$+\left(\mathrm{C} \mathrm{Q}^{* \beta}-\mathrm{c}_{\mathrm{s}}\right) \mathrm{R}\left(\mathrm{Q}^{*}\right)=0$

the minimum expected total cost is given by:

$\min E(T C)$

$=\mathrm{c}_{\mathrm{p}} \mathrm{Q}^{*}+\mathrm{c}_{\mathrm{h}} \mathrm{Q}^{* \beta}\left(\mathrm{Q}^{*}-\frac{\mu}{2}\right)-\frac{\left(\mathrm{c}_{\mathrm{h}} \mathrm{Q}^{* \beta}+\mathrm{c}_{\mathrm{s}}\right)\left(\mathrm{Q}^{*}-\mu\right)}{2} \mathrm{e}^{-\frac{\mathrm{Q}^{*}}{\mu}}$

$+\frac{\left(\mathrm{c}_{\mathrm{h}} \mathrm{Q}^{* \beta}+\mathrm{c}_{\mathrm{s}}\right) \mathrm{Q}^{* 2}}{2 \mu} \Gamma\left(0, \frac{\mathrm{Q}^{*}}{\mu}\right)$ 
Table 1: the optimal purchase quantity that minimizes the relevant expected total cost for the period and meet the constraint $\mathrm{E}(H C) \leq 10$ for the different values of $\beta$

\begin{tabular}{lllllll}
\hline$\beta$ & \multicolumn{2}{l}{ Uniform Distribution } & \multicolumn{2}{l}{ Exponential Distribution } & \multicolumn{2}{c}{ Laplace Distribution } \\
\hline & $\mathrm{Q}^{*}$ & $\min E(T C)$ & $Q^{*}$ & $\min E(T C)$ & $Q^{*}$ & $\min E(T C)$ \\
\hline 0 & 32.07 & 32.62 & 30.42 & 57.01 & 30.99 & 48.64 \\
0.1 & 25.84 & 39.69 & 24.15 & 6.58 & 24.63 & 59.02 \\
0.2 & 21.48 & 49.23 & 19.85 & 76.29 & 20.16 & 71.26 \\
0.3 & 18.25 & 59.44 & 16.73 & 85.56 & 16.81 & 84.49 \\
0.4 & 15.79 & 69.36 & 14.41 & 93.99 & 14.19 & 98.12 \\
0.5 & 13.87 & 78.62 & 12.62 & 101.54 & 12.06 & 11.96 \\
0.6 & 12.35 & 87.01 & 11.19 & 108.35 & 10.29 & 139.92 \\
0.7 & 11.09 & 94.64 & 10.05 & 114.39 & 8.76 & 154.05 \\
0.8 & 10.07 & 101.44 & 9.12 & 119.71 & 7.45 & 167.76 \\
0.9 & 9.21 & 107.56 & 8.34 & 124.49 & 6.33 & 180.63 \\
1 & 8.48 & 113.03 & 7.69 & 128.75 & 5.38 & \\
\hline
\end{tabular}

* Demand during the period follows the Laplace distribution

Assume that the demand during the period follows the laplace distribution with mean $\mu$ and variance $2 \theta^{2}$, then we can get the optimal purchase quantity as follows:

$$
\mathrm{E}(\mathrm{x})=\mu \quad, \quad \mathrm{V}(\mathrm{x})=2 \theta^{2} \quad, \quad \mathrm{~F}(\mathrm{Q})=1-\frac{1}{2} \mathrm{e}^{-\frac{\mathrm{Q}-\mu}{\theta}},
$$$$
\mathrm{R}(\mathrm{Q})=\frac{1}{2} \mathrm{e}^{-\frac{\mathrm{Q}-\mu}{\theta}}
$$$$
\text { and } \int_{0}^{\mathrm{Q}} \mathrm{xf}(\mathrm{x}) \mathrm{dx} \cong \mu-(\mathrm{Q}+\theta) \mathrm{R}(\mathrm{Q}), \mathrm{Q}>\mu
$$$$
\text { also, } \int_{\mathrm{Q}}^{\infty} \frac{\mathrm{f}(\mathrm{x})}{\mathrm{x}} \mathrm{dx}=\frac{1}{2 \theta} \mathrm{e}^{\frac{\mu}{\theta}} \Gamma\left(0, \frac{\mathrm{Q}}{\theta}\right), \mathrm{Q}>\mu
$$

Substituting in equation (9), the optimal purchase quantity $\mathrm{Q}^{*}$ is the solution of the following equation:

$$
\begin{aligned}
& {\left[\mathrm{A} \mathrm{F}\left(\mathrm{Q}^{*}\right)+\mathrm{CR}\left(\mathrm{Q}^{*}\right)\right] \mathrm{Q}^{* \beta}} \\
& +\frac{\mathrm{Q}^{*}}{2 \theta} \mathrm{e}^{\frac{\mu}{\theta}}\left(\mathrm{BQ}^{* \beta}+\mathrm{c}_{\mathrm{s}}\right) \Gamma\left(0, \frac{\mathrm{Q}^{*}}{\theta}\right) \\
& -\mathrm{C} \mathrm{Q}^{* \beta-1}\left[\mu-\theta \mathrm{R}\left(\mathrm{Q}^{*}\right)\right]+\mathrm{c}_{\mathrm{p}}-\mathrm{c}_{\mathrm{s}} \mathrm{R}\left(\mathrm{Q}^{*}\right)=0 .
\end{aligned}
$$

And the minimum expected total cost is: $\min E(T C)=$

$$
\begin{aligned}
& \mathrm{c}_{\mathrm{p}} \mathrm{Q}^{*}+\mathrm{c}_{\mathrm{h}} \mathrm{Q}^{* \beta}\left(\mathrm{Q}^{*}-\frac{\mu}{2}\right)+\frac{\left(\mathrm{c}_{\mathrm{h}} \mathrm{Q}^{* \beta}+\mathrm{c}_{\mathrm{s}}\right)\left(\theta-\mathrm{Q}^{*}\right)}{4} \mathrm{e}^{-\frac{\mathrm{Q}^{*}-\mu}{\theta}} \\
& +\frac{\left(\mathrm{c}_{\mathrm{h}} \mathrm{Q}^{* \beta}+\mathrm{c}_{\mathrm{s}}\right) \mathrm{Q}^{* 2}}{4 \theta} \mathrm{e}^{\frac{\mu}{\theta}} \Gamma\left(0, \frac{\mathrm{Q}^{*}}{\theta}\right)
\end{aligned}
$$

4-Special cases: We deduce four special cases for our model as follows:

Case 1: For equation (9) let $\lambda=0$ and $\beta=0 \Rightarrow \mathrm{C}_{\mathrm{h}}(\mathrm{Q})=\mathrm{c}_{\mathrm{h}}, \mathrm{A}=\mathrm{B}=\mathrm{c}_{\mathrm{h}}$ and $C=0$, then the optimal purchase quantity given by:

$$
F\left(Q^{*}\right)+Q^{*} \int_{Q^{*}}^{\infty} \frac{f(x)}{x} d x=\frac{c_{s}-c_{p}}{c_{s}+c_{h}}
$$

This is unconstrained single period stochastic inventory model with uniform demand and constant unit costs, which is agree with the result of Fabrycky ${ }^{[6]}$.

Case 2: For equation (10), let $\lambda=0$ and $\beta=0 \Rightarrow \mathrm{C}_{\mathrm{h}}(\mathrm{Q})=\mathrm{c}_{\mathrm{h}}, \mathrm{A}_{1}=\mathrm{B}=\mathrm{c}_{\mathrm{h}}$ and $C=0$. Then the following relation for $\mathrm{Q}^{*}$ can be obtained:

$\mathrm{Q}^{*} \ln \frac{\mathrm{eb}}{\mathrm{Q}^{*}}=\frac{\mathrm{b}\left(\mathrm{c}_{\mathrm{s}}-\mathrm{c}_{\mathrm{p}}\right)}{\mathrm{c}_{\mathrm{s}}+\mathrm{c}_{\mathrm{h}}}$

This is unconstrained single period stochastic inventory model with demand uniformly distributed and constant unit costs, , which is agree with the result of Taha $^{[9]}$.

Case 3: For equation (13), let $\lambda=0$ and $\beta=0 \Rightarrow \mathrm{C}_{\mathrm{h}}(\mathrm{Q})=\mathrm{c}_{\mathrm{h}}, \mathrm{A}=\mathrm{B}=\mathrm{c}_{\mathrm{h}}$, and $\mathrm{C}=0$, then the optimal purchase quantity $\mathrm{Q}^{*}$ is:

$\mathrm{F}\left(\mathrm{Q}^{*}\right)+\frac{\mathrm{Q}^{*}}{\mu} \Gamma\left(0, \frac{\mathrm{Q}^{*}}{\mu}\right)=\frac{\mathrm{c}_{\mathrm{s}}-\mathrm{c}_{\mathrm{p}}}{\mathrm{c}_{\mathrm{s}}+\mathrm{c}_{\mathrm{h}}}$

This is unconstrained single period stochastic inventory model with demand exponentially distributed and constant unit costs.

Case 4: For equation (16), let $\lambda=0$ and $\beta=0 \Rightarrow \mathrm{C}_{\mathrm{h}}(\mathrm{Q})=\mathrm{c}_{\mathrm{h}}, \mathrm{A}=\mathrm{B}=\mathrm{c}_{\mathrm{h}}$, and $\mathrm{C}=0$, then the optimal purchase quantity $\mathrm{Q}^{*}$ is:

$\mathrm{F}\left(\mathrm{Q}^{*}\right)+\frac{\mathrm{Q}^{*}}{2 \theta} \mathrm{e}^{\frac{\mu}{\theta}} \Gamma\left(0, \frac{\mathrm{Q}^{*}}{\theta}\right)=\frac{\mathrm{c}_{\mathrm{s}}-\mathrm{c}_{\mathrm{p}}}{\mathrm{c}_{\mathrm{s}}+\mathrm{c}_{\mathrm{h}}}$

This is unconstrained single period stochastic inventory model with constant unit costs and the uniform demand follows laplace distribution.

Illustrative example: Consider the following single period uniform inventory model with parameters given as: $\mathrm{c}_{\mathrm{p}}=0.5, \mathrm{c}_{\mathrm{h}}=0.5, \mathrm{c}_{\mathrm{s}}=15.5$ and $K=10$. We will determine the optimal purchase quantity when:

* the demand during the period uniformly distributed, $b=50$, 
* the demand during the period exponentially distributed, $\mu=25$,

* the demand during the period is Laplace distributed, $\mu=25$ and $\theta=17.68$.

Using equations (10), (13) and (16) by testing different values of $\lambda$, we can get the optimal purchase quantity that minimizes the relevant expected total cost for the period and meet the constraint $E(H C)$ $\leq 10$ for the different values of $\beta$ as shown in Table 1:

The solution of the problem may be determined more readily by plotting $\min E(T C)$ against $\beta$ for each distributions of demand as the following Figure2:

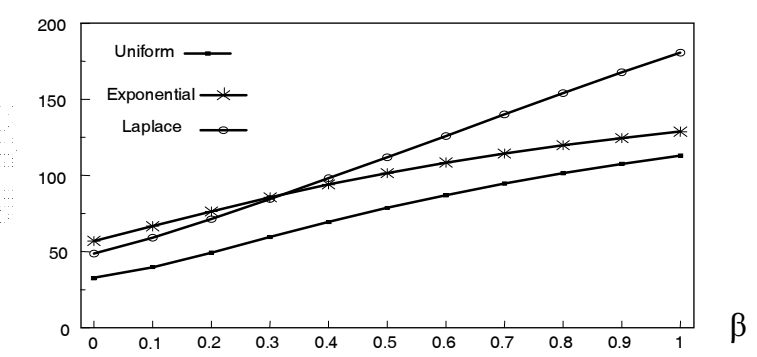

Figure2: $\min E(T C)$ against $\beta$ for each distributions of demand

\section{CONCLUSION}

This article derives the optimal solution for constrained single period stochastic uniform inventory model that considering continuous distributions of demand and varying holding cost. We have evaluated Q* that minimizes the relevant expected total cost for the period for each value of $\beta$. Also, for our example, at the same inventory parameters we found that the min $\mathrm{E}(\mathrm{TC})$ in the case of the demand uniformly distributed is less than the min E(TC) in the cases when the demand during the period follows the exponential or the Laplace distributions for all different values of $B$.

\section{REFERENCES}

1. Gould, F.J., G.D. Eppen and C.P. Schmidt, 1997. Introductory Management Science. Prentice-Hall International, Inc.

2. Nahmias, S., 1993). Production and Operations Analysis. 2nd Ed. Irwin, Inc.

3. Tersine, R.J., 1994. Principles of Inventory and Materials Management. 4th Ed. Prentice-Hall, Inc.

4. Silver, E.A. and R. Peterson, 1985. Decision Systems for Inventory Management and Production Planning. New York, John Wiley and Sons.

5. Hadley, G. and T.M. Whitin, 1963. Analysis of Inventory Systems. Englewood Cliffs, N.J., Prentice-Hall.

6. Fabrycky, W.J. and J. Banks, 1967. Procurement and Inventory System: Theory and Analysis. Reinhold Publishing Corporation, USA.

7. Abou-El-Ata, M.O., H.A. Fergany and M.F. E1Wakeel, 2003. Probabilistic Multi-item Inventory Model With Varying Order Cost Under Two Restrictions: A Geometric Programming Approach. Intl. J. Productions Economics, 83: 223-231.

8. Fergany, H.A. and M.F. El-Wakeel, 2004. Probabilistic Single-Item Inventory Problem with Varying Order Cost Under Two Linear Constraints. J. Egypt. Math. Soc., 12: 71-81.

9. Taha, H., 1997. Operations Research. 6th Ed. Englewood Cliffs, N.J., Prentice-Hall. 